\title{
Behaviour Change: An Editorial Statement
}

\author{
Alan Hudson \\ Royal Melbourne Institute of Technology
}

As the new editor of Behaviour Change, I would like to begin this editorial statement by thanking Matt Sanders, the outgoing editor. After developmental periods under the editorship of first Neville King and then Jay Birnbrauer, Matt took over in 1992 and has overseen the consolidation of Behaviour Change as a high-quality Australian journal.

This issue of Behaviour Change is the first since the host organisation has changed its name from the Australian Behaviour Modification Association (ABMA) to the Australian Association for Cognitive and Behaviour Therapy (AACBT). Partly because I do not think that it is a good thing to change too many things at one time, but mostly because my editorial predecessors have established a sound enterprise, I do not foreshadow any major changes to the operation of the journal. However, there are some changes of emphasis that I think would contribute to its ongoing development.

The first of these relates to the fact that most of our subscribers are practitioners, and as practitioners would probably appreciate more entries in the journal which are examples of good clinical practice, rather than good research articles. In terms of our editorial policy, we would still want to publish "empirical studies" and "review articles", but we would like to encourage practitioners to submit more "case studies" and "clinical notes".

Practitioners who follow the scientist-practitioner model routinely collect data and are in a position to write up case studies which would be of interest to other practitioners. While empirical researchers would normally require reversal or multiple baseline designs to demonstrate functional control over the dependent variable, practitioners almost universally rely upon $\mathrm{AB}$ designs (hopefully with follow-up) to satisfy themselves that the required behaviour change has occurred. It is important for continued improvement in clinical practice that examples of successful interventions be made readily available to behavioural practitioners. I urge practitioners out there to submit examples of their work. Some good examples of previously published case studies are Bradley and Houghton (1992), Dixon, Moore, Harnett, Howard, and Petrie (1995), and Halford and Miller (1992). It is interesting to note that many students in post graduate courses are required to submit case studies as part of their course requirements. Unfortunately, very few are encouraged to submit them for publication, and much good work goes relatively unnoticed.

In addition to "case studies" which report interventions, many practitioners and researchers will have information that is useful to other practitioners. This information can be submitted as "clinical notes". Some good examples of previously published clinical notes are MacDougall (1992) and Wilks (1994).

Case studies and clinical notes will, of course, continue to be evaluated through the journal's established peer review process.

A second change in emphasis that I would encourage is the publication of papers from authors outside of Australia. It is interesting to note that, of the seven articles in this issue, an Australian resident is the first author in only two of them. Three first authors are from New Zealand, one is from Canada, and one is from Malaysia. Whereas past issues have had many articles from New Zealand and North America, very few articles have originated from our South-East Asian neighbours. It would be pleasing if we could attract more contributions from this important geographical area. Perhaps readers with colleagues in this region could 
encourage them to consider Behaviour Change as an outlet for their work.

\section{REFERENCES}

Bradley, L., \& Houghton, S. (1992). The reduction of inappropriate sucking behaviour in a 7-year-old girl through response-cost and social-reinforcement procedures. Behaviour Change, 9, 254-257.

Dixon, T.S., Moore, D.W., Hartnett, N., Howard, T., \& Pertrie, K. (1995). Reducing inappropriate questioning behaviour in an adolescent with autism: A case study.
Behaviour Change, 12, ??-??.[(page nos to be inserted]).

Halford, W.K., \& Miller, S. (1992). Cognitive behavioural stress management as treatment of atopic dermatitis: A case study. Behaviour Cchange, 9, 19-24.

MacDougall, C. (1992). Collecting parent reports of behaviour: A clinical note. Behaviour Change, 9, $50-51$.

Wilks, R. (1994). A consultation and training role for the behaviourally oriented educational psychologist in school settings: A clinical note. Behaviour Change, 11, 121-125. 